\title{
Antiserotoninergic Activity of 2-Aminoethylbenzocyclanones in Rat Aorta: Structure-Activity Relationships
}

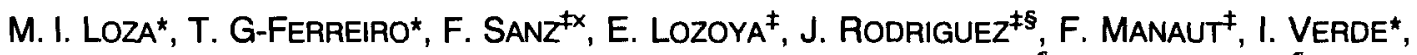 \\ E. Castro*, J. A. Fontenla*, I. Cadavid*, M. HonRubia*, J. Fueyo", and E. Raviña" \\ Received January 16, 1992, from the *Department of Pharmacology, University of Santiago, E-15706 Santiago de Compostela, Spain, the \\ ${ }^{\ddagger}$ Department of Medical Informatics, Institut Municipal d'Investigació Mèdica, Universitat Autonoma de Barcelona, Passeig Maritim 25 , \\ E-08003 Barcelona, Spain, and the Departments of "Physical Chemistry and "Organic Chemistry (Section of Pharmaceutical Chemistry), \\ University of Santiago, E-15706 Santiago de Compostela, Spain. Accepted for publication October 13, 1992.
}

\begin{abstract}
The antiserotoninergic activity at the serotonin receptor subtype $2\left(5-\mathrm{HT}_{2}\right)$ of seven new 2-aminoethylbenzocyclanones was determined with respect to serotonin-induced contractions in rat aorta and compared with that of ketanserine $\left(\mathrm{p} A_{2}=8.87\right)$. Competitive antagonism was observed in six compounds $\left(6.72 \leq p A_{2} \leq 8.12\right)$. Three-dimensional structures and molecular electrostatic potential distributions of ketanserine and 2-aminoethylbenzocyclanones were analyzed. Several molecular features correlated with the rank of antiserotoninergic activity. In the case of the cyclanone fragment, the rank of activity was associated with the degree of planarity of the bicyclic system. The steric and electrostatic effects due to the loss of planarity were analyzed. In the case of the amino moiety, activity was associated with a particular spatial pattern defined by the amino nitrogen, the aromatic system, and molecular electrostatic potential minima generated by the oxygen atom.
\end{abstract}

Substantial evidence for the existence of multiple serotonin (5-HT) receptor subtypes has recently been provided. ${ }^{1-6}$ The increasing availability of compounds with selectivity and potency for individual 5-HT receptor subtypes has contributed to remarkable advances in the understanding of 5-HT neurotransmission. ${ }^{2-4}$ The identification of 5-HT receptor antagonist properties of ketanserine has been a key development in this field. The importance of this compound relates to its ability to discriminate $5-\mathrm{HT}_{2}$ from other 5 -HT sites. Numerous ketanserine analogues [i.e., setoperone, pirenperone, and altanserin (see structure)] have been developed with the aim of improving selectivity. Some of these analogues have been studied with respect to their potential for treating anxiety, depression, schizophrenia, and other psychiatric disorders, 6,7 Although ketanserine has shown no effect, these compounds bear a benzoylpiperidine residue in which a neuroleptic pharmacophore similar to the butyrophenone fragment has been described. ${ }^{8}$ Moreover, the butyrophenone fragment interacts with various central receptors involved in behavioral responses. For instance, spiperone, an antagonist of $\mathrm{D}_{2}$ receptors, has a high affinity for $5-\mathrm{HT}_{2}$ sites. $^{3}$

The synthesis and antidopaminergic effects of 2-and 3-aminomethyltetralones (1 and 2 , respectively) have been previously reported by our group.7,9-11 These compounds are semirigid variants of the general neuroleptic structure ArC4N (an aromatic ring + four carbon atoms + an amino function). In addition, we have recently described the $5-\mathrm{HT}_{2}$ antagonist activity of some 3-aminomethyltetralones $\mathbf{2 . 1 2}$ Compounds $\mathbf{2 a}, \mathbf{2 b}$, and $2 \mathrm{c}$ that bear a butyrophenone fragment acted as inhibitors of the binding of ketanserine to $5-\mathrm{HT}_{2}$ receptors and showed a degree of activity similar to that of methysergide.

It has been suggested that serotoninergic activity requires the presence of an aromatic or heteroaromatic ring, which<smiles>Nc1ccc2c(=O)n(CCN3CCC(C(=O)c4ccc(F)cc4)CC3)c(=O)[nH]c2c1</smiles><smiles></smiles><smiles>O=C(c1ccc(F)cc1)C1CCN(CCn2c(=S)[nH]c3ccccc3c2=O)CC1</smiles><smiles>Cc1nc2ccccn2c(=O)c1CCN1CCC(C(=O)c2ccc(F)cc2)CC1</smiles><smiles>O=C(CCCN1CCC2(CC1)C(=O)NCN2c1ccccc1)c1ccc(F)cc1</smiles>

generates a particular molecular electrostatic potential (MEP) pattern, as well as an aliphatic chain substituted with a basic protonable amino group that is placed at a particular distance of the aromatic system. ${ }^{13-16}$ This distance is often generated by a two-carbon aliphatic chain.

We studied $5-\mathrm{HT}_{2}$ antagonistic activity in a series of 2-aminoethylbenzocyclanones (see structures) which bear both the butyrophenone and $p$-fluorobenzoylpiperidine fragments. These fragments have aromatic or heteroaromatic rings and amino groups separated by two-carbon aliphatic chains. The activity of these compounds was measured in rat aorta rings stripped of endothelium, a preparation that contains $5 \cdot \mathrm{HT}_{2}$ receptors. ${ }^{17}$ To determine complementary molecular characteristics associated with antiserotoninergic activity, the relationship between activity and structural modifications made to cyclanone and amine residues, with ketanserine as a reference, was analyzed. 


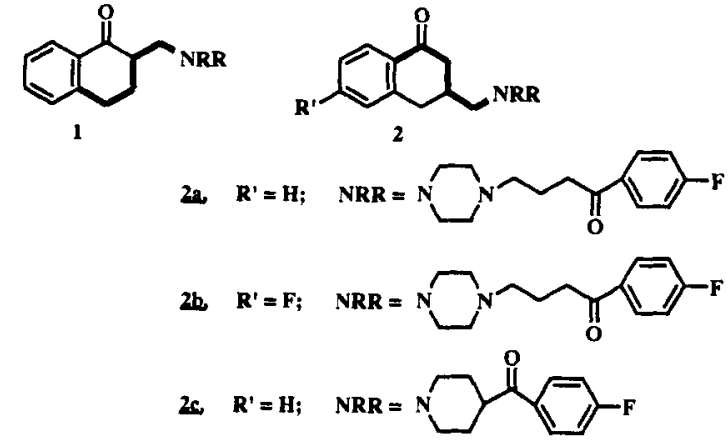

2- and 3-Aminomethyltetratones

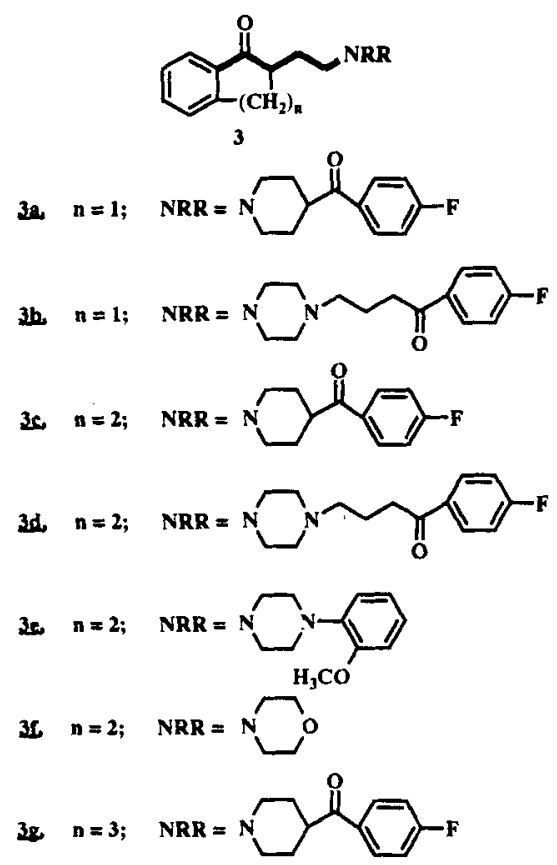

2-Aminoethylbenzocyclanones

\section{Experimental Section}

Chemistry-The following 2-aminoethylbenzocyclanones, prepared by two of the authors (J.F. and E.R.) and co-workers, ${ }^{18}$ were studied: 2 - $[\beta$-(4-p-fluorobenzoyl)- $N$-piperidinylethyl $)]-1$-indanone hydrochloride (3a; mp, 264-266 $\left.{ }^{\circ} \mathrm{C}\right) ; 2-\left[\beta-\left(N^{4}-(\gamma-p\right.\right.$-fluorobenzoyl)propyl]- $N^{1}$-piperazinyl-ethyl]-1-indanone dihydrochloride $(3 \mathbf{b} ; \mathrm{mp}$, $210-214{ }^{\circ} \mathrm{C} ; 2-[\beta$-(4-p-fluorobenzoyl)- $N$-piperidinilethyl]-1-tetralone hydrochloride (3c; mp, $\left.224-225^{\circ} \mathrm{C}\right) ; 2-\left[\beta-\left(N^{4}-(\gamma-p\right.\right.$-fluorobenzoyl)propyl]- $N^{1}$-piperazinylethyl]-1-tetralone dihydrochloride (3d; mp, $\left.235-238^{\circ} \mathrm{C}\right) ; 2-\left[\beta-\left(N^{4}-0\right.\right.$-methoxyphenyl- $N^{1}$-piperazinylethyl $\left.)\right]-1-$ tetralonedihydrochloride (3e; mp, 279-281 $\left.{ }^{\circ} \mathrm{C}\right)$; 2 - $(\beta$-morpholinoethyl)-1-tetralone hydrochloride (3f; $\left.\mathrm{mp}, 251-253^{\circ} \mathrm{C}\right) ; 2-[\beta$ - $(4-p$ fluorobenzoyl)- $N$-piperidinylethyl]-1-benzosuberone hydrochloride $\left(3 \mathrm{~g} ; \mathrm{mp}, 220-223^{\circ} \mathrm{C}\right.$ ) (see structures).

Pharmacology-5- $\mathrm{HT}_{2}$ receptor activity was studied in aorta preparations from 250-300-g Sprague-Dawley rats (bred at the animal facilities, University of Santiago, Spain) that were killed by cervical dislocation and carotid arteriotomy. The descending aorta was removed, cleaned, stripped of endothelium, and cut into rings of 4-mm length. Rings were mounted and placed under tension (1300 $\mathrm{mg}$ ) in an isolated organ bath containing $20 \mathrm{~mL}$ of Krebs solution at $37^{\circ} \mathrm{C}$ that aerated with carbogen $\left(95 \% \mathrm{O}_{2}, 5 \% \mathrm{CO}_{2}\right)$. Following equilibration for $60 \mathrm{~min}$, cumulative concentration-effect curves were constructed for 5 -HT ( $30 \mathrm{nM}$ to $100 \mu \mathrm{M}$ ) until two identical control curves were obtained by Van Rossum's method. ${ }^{19}$ Ketanserine and the compounds to be tested were incubated for $15 \mathrm{~min}$ prior to the construction of 5-HT concentration-effect curves. Isometric contractions were monitored with a CPOL 0-25-g transducer connected to a CELASTER IOS-1 computerized organ bath. Competitive antagonism was quantified by Schild plot analysis ${ }^{20}$ for three successive concentrations of the antagonist, thus allowing calculation of the $\mathrm{pA}_{2}$ value. Each experiment was performed in four animals.

Structure-Activity Relationships-The structure of the compounds tested can be represented as $\mathrm{X}-\mathrm{CH}_{2}-\mathrm{CH}_{2}-\mathrm{Y}$, where $\mathrm{X}$ is the cyclanone residue and $Y$ the amine residue (Figure 1). These residues were studied separately. The geometries of fragments $\mathrm{X}$ (Figure 1A)

A<smiles>Cn1c(=O)[nH]c2ccccc2c1=O</smiles><smiles>CC1Cc2ccccc2C1=O</smiles><smiles></smiles>
$x_{2}$ $\mathbf{8 . 8 7}$ 8.12<smiles>CC1CCc2ccccc2C1=O</smiles><smiles>CC1CCCc2ccccc2C1=O</smiles>

$x_{3}$ 7.45

B<smiles>CN1CCC(C(=O)c2ccc(F)cc2)CC1</smiles>
$Y_{1}$ 7.45<smiles>CN1CCN(CC(=O)c2ccc(F)cc2)CC1</smiles>
$\mathrm{Y}_{2}$ 7.35
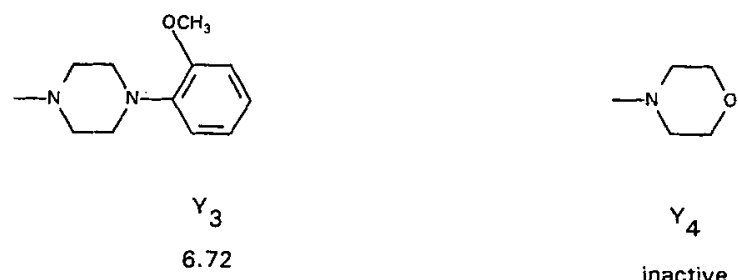

Figure 1-The compounds share the general formula $X-\mathrm{CH}_{2}-\mathrm{CH}_{2}-Y$ : (A) fragments $X$ of compounds with fragment $Y=Y_{1}$; (B) fragments $Y$ of compounds with fragment $X=X 3$. Numbers below the name of each compound correspond to $p A_{2}$ values. Compounds are presented in order of decreasing activity. 
Table I-Competitive Antagonism of $5-\mathrm{HT}_{2}$

\begin{tabular}{lcc}
\hline Compound & $\mathrm{pA}_{2}$ & Slope of Schild Plot \\
\hline 3a & $\mathbf{8 . 1 2 \pm 0 . 1 1}$ & 0.76 \\
3b & $7.30 \pm 0.05$ & 0.72 \\
3c & $7.45 \pm 0.52$ & 1.24 \\
3d & $7.35 \pm 0.85$ & 0.72 \\
3e & $6.72 \pm 0.06$ & 1.13 \\
3f & $-\mathbf{a}$ & $-\mathbf{a}$ \\
3g & $6.75 \pm 0.045$ & 0.75 \\
Ketanserine & $\mathbf{8 . 8 7 \pm 0 . 1 1}$ & 0.82 \\
\hline
\end{tabular}

a Inactive.

were built with the BIOSYM molecular modeling program and fully optimized by the AM1 method ${ }^{21}$ included in the AMPAC program. ${ }^{22}$ For each optimized geometry, STO-3G ab initio wave functions were calculated with the GAUSSLAN'90 program. ${ }^{23}$ These wave functions were then used to calculate MEP distributions where MEP minima were located with the MEPMIN program. ${ }^{24}$

In the case of fragments $Y$ (Figure 1B), structural fittings of Y2, Y3, and $Y 4$ on $Y 1$ were attempted. Structures of fragments $Y$ were built and optimized as fragments $X$. In the case of the reference molecule $Y 1$, several starting conformers were considered to avoid local minima. Rotations around single bonds were carried out in fragments $\mathrm{Y} 2$ and $\mathrm{Y} 3$ in an attempt to fit the structure of $\mathrm{Y} 1$.

\section{Results and Discussion}

The antiserotoninergic activity of ketanserine and the series of 2-aminoethylbenzocyclanones was evaluated with respect to 5-HT-induced contractions in rat aorta without endothelium. Activity was quantified by Schild plot analysis with three different concentrations for each compound.

Ketanserine and six of the compounds studied (3a, $3 \mathbf{b}, \mathbf{3 c}$, 3d, $3 \mathbf{e}$, and $3 \mathrm{~g}$ ) showed competitive antagonism of 5-HT
(Table I). Those compounds concentration-dependently shifted the 5-HT concentration-response curve to the right, with no depression of the maximum effect. In Schild plot analysis, slopes did not differ significantly from one, and $\mathrm{pA}_{2}$ values indicated an important antagonist effect. Compound $3 \mathbf{f}$ was inactive.

Structure-activity relationships of cyclanone (X) and amine fragments $(Y)$ were investigated separately. First, we analyzed those compounds with fragment $Y$ constant but with variations in $X$ (3a, $\mathbf{3 c}, \mathbf{3 g}$ and ketanserine; Figure 1A), searching for molecular properties to explain the order of activity observed: $\mathrm{X} 1>\mathrm{X} 2>\mathrm{X} 3>\mathrm{X} 4$. Analyses were performed considering the optimized geometries and the MEP distributions of these fragments. Several correlations between molecular characteristics and the degree of activity were found. First of all, the optimized geometries of the $\mathrm{X}$ fragments indicated that the structure $\mathrm{X} 1$ is completely planar (Figure 2A). The same was true for X2 when the hydrogens of its five-member ring were discarded (Figure 2B). On the other hand, the six-member ring of X3 showed significant deviations from planarity: there is a carbon atom placed $0.58 \AA$ from the plane of the aromatic ring. The seven-member ring in $\mathrm{X} 4$ presented the largest deviation from planarity (Figure 2D). After analyzing several lowenergy conformations of this ring, we took the most planar of them. In spite of this, there are atoms far from the plane defined by the aromatic system (the most extreme case is a carbon atom placed at $1.85 \AA$ ). Furthermore, in $\mathrm{X} 1$ (present in ketanserine, the most active molecule) and X2, the deepest MEP minima (generated by lone pairs of an oxygen atom) are located in the molecular plane (Figures $2 \mathrm{~A}$ and $2 \mathrm{~B}$ ), whereas the oxygen in $\mathrm{X} 3$ generates minima at 0.08 and $0.18 \AA$ from the molecular plane (Figure $2 \mathrm{C}$ ). The MEP minima generated by the oxygen of X4 are far from the plane (0.66 and $1.12 \AA$ ).
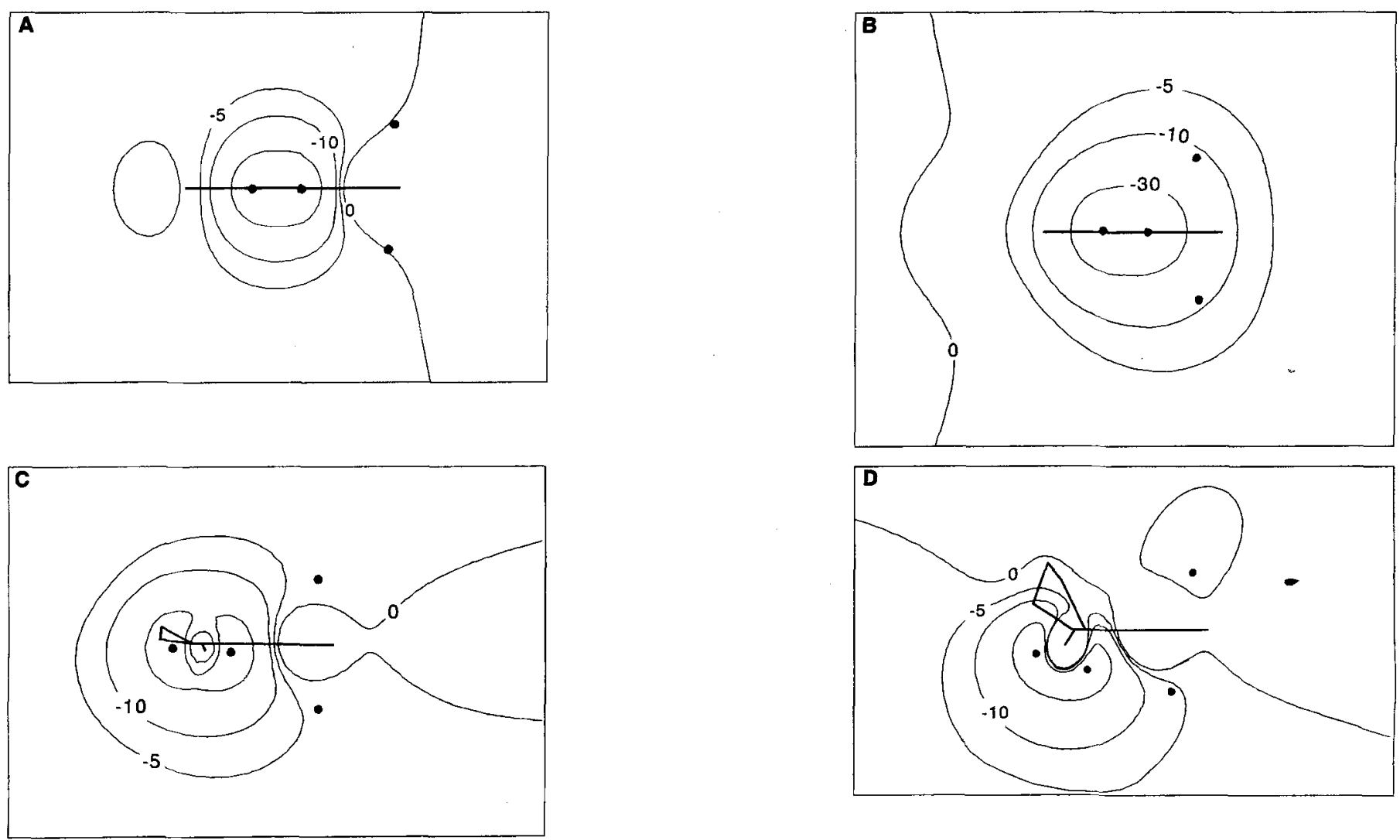

Figure 2-MEP maps of fragments $X$ on a plane perpendicular to the aromatic ring. The plane contains the MEP minima generated by the carbonyl group vicinal to the ring: (A) X1; (B) X2; (C) X3; (D) X4. 
A

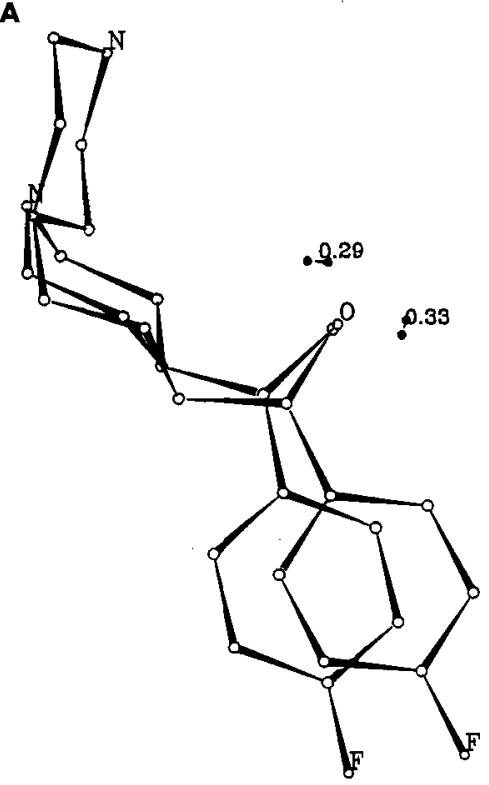

$\mathbf{B}$

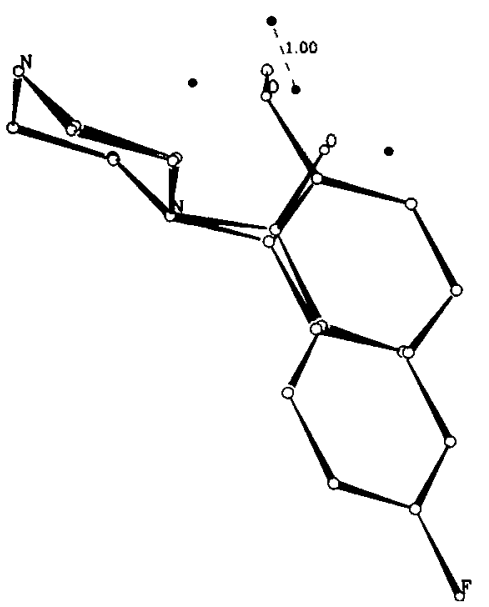

c

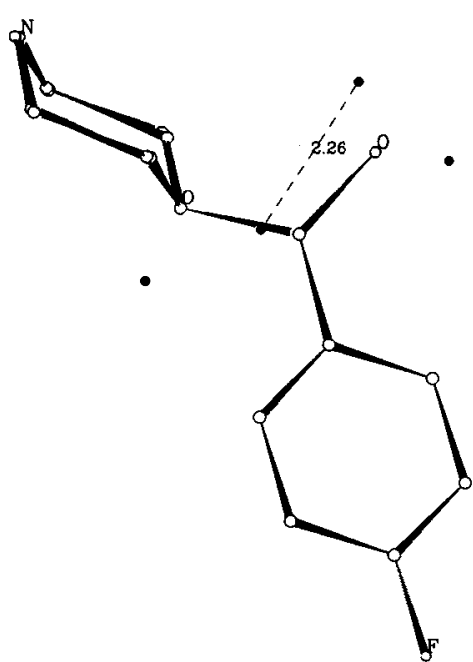

Figure 3-Structural superposition of the fragments $Y$ showing distances between MEP minima generated by the oxygen atoms (A) $Y 1$ versus $Y 2$; (B) Y1 versus Y3; (C) Y1 versus Y4.

Another aspect of MEP distribution correlating with activity related to the symmetry of this distribution with reference to the aromatic ring. MEP distributions of X1 and X2 are totally

symmetrical, that of $\mathrm{X} 3$ is slightly asymmetrical, and that of $\mathrm{X} 4$ is markedly asymmetrical.

Secondly, we analyzed those compounds with fragment $X$ constant but with variations in $Y(\mathbf{3 c}, 3 \mathbf{3 d}, \mathbf{3 e}$ and $\mathbf{3 f}$; Figure 1B) to explain the order of activity observed: Y1 $>$ Y2 $>$ Y3 $>$ Y4. Given the conformational degrees of freedom of these molecules, flexible structural fitting of $\mathrm{Y} 2, \mathrm{Y} 3$, and $\mathrm{Y} 4$ on $\mathrm{Y} 1$ was attempted (Figures 3A-3C). The three fittings were executed overlapping first the six-member nitrogencontaining rings. Thereafter, coincidence in the same plane was achieved for the aromatic rings present in Y1, Y2, and Y3 by rotations around single bonds of Y2 and Y3 (Figures 3A and $3 \mathrm{~B}$ ). Although it is possible to place the three phenyl groups in a common plane, they become closer in the case of Y2 and Y1 (Figure 3A; $1 \AA$ between the center of the rings) than in the case of $\mathrm{Y} 3$ and $\mathrm{Y} 1$ (Figure $3 \mathrm{~B} ; 2.2 \AA$ between the center of the rings). The absence of phenyl group in Y4 could be related to the lack of activity of the corresponding compound. The last aspect that was considered in this set of fittings is the proximity between the oxygen-generated MEP minima (obtained with MEPMIN as described above). In the case of fragment $\mathrm{Y} 3$ the methoxy group was rotated around the $\mathrm{C}-\mathrm{O}$ single bond with the aim of bringing the MEP minima as close as possible. In the fitting between Y2 and Y1, the distance between minima is $0.3 \AA$ (Figure $3 \mathrm{~A}$ ). In the case of $\mathrm{Y} 3$ versus $\mathrm{Y} 1$, this distance is at least $1 \AA$ (Figure 3B). MEP minima generated by the lone pairs of the oxygen atom of $\mathrm{Y} 4$ cannot be located $<2.5 \AA$ from the minima generated by the oxygen of $\mathrm{Y} 1$ (Figure 3C). The ranking of activities of the compounds agreed with the ranking of proximities of the phenyl groups and the oxygen-generated MEP minima versus the same groups in the more active compound (containing the fragment $\mathrm{Y} 1$ ).

In conclusion, six of the seven 2-aminomethylcyclanones tested proved to be antagonists of 5-HT in rat aorta. Compound $3 \mathrm{~b}$ presented an activity comparable to that of ketanserine. The structural requirements for the cyclanone fragment to contribute to activity appeared to be related to the planarity of the molecule, the symmetry of the MEP distribution, and the location of main MEP minima in the molecular plane. In the amino fragments, the $5-\mathrm{HT}_{2}$ antiserotoninergic activity appeared to be related to the presence of both an aromatic ring and a MEP minimum generated by an heteroatom placed in certain positions versus the amino nitrogen.

\section{References and Notes}

1. Bradley, P. B.; Engel, G.; Feniuk, W.; Fozard, J. R.; Humphrey, P. P. A.; Midlemiss, D. N.; Mylecharane, E. J.; Richardson, B. P.; Saxena, P. R. Neuropharmacol. 1986, 25, 563-576.

2. Leff, P.; Martin, G. R. Med. Res. Rev. 1988, 8, 187-202.

3. Frazer, A.; Maayani, S.; Wolfe, B. B. Ann. Rev. Pharmacol. Toxicol. 1990, 30, 307-348.

4. Palacios, J. M.; Waeber, C.; Hoyer, D.; Mengod, G. Ann. N.Y. Acad. Sci. 1991, 600, 36-52.

5. Watson, S.; Abbott, A. In Receptor Nomenclature Supplement. TiPS. Elsevier: Cambridge, U.K., 1990.

6. Fozard, J. R. Trends Pharmacol. Sci. 1987, 8, 501-506.

7. Cortizo, L.; Santana, L.; Ravin̄a, E.; Orallo, F.; Fontenla, J. A.; Castro, E.; Calleja, J. M.; Ceballos, M. L. J. Med. Chem. 1991, 34, 2242-2247.

8. Boswell, R. F., Jr.; Welstead, W. J., Jr.; Duncan, R. L., Jr.; Johnson, D. N.; Funderburk, W. H. J. Med. Chem. 1978, 21, 136-139.

9. Eirin, A.; Ravina, E.; Montanes, J. M.; Calleja, J. M. Eur. J. Med. Chem. 1976, 11, 29-32.

10. Eirin, A.; Santana, L.; Raviña, E.; Fernandez, F.; SanchezAbarca, E.; Calleja, J. M. Eur. J. Med. Chem. 1978, 13, 533-537.

11. Santana, L.; Raviña, E.; Eirin, A.; Sanchez-Abarca, E.; Calleja J. M. In Proceedings of the VII International Symposium on Medicinal Chemistry; Torremolinos, 1980; p 173.

12. Loza, M. I.; Verde, I.; Castro, E.; Orallo, F.; Fontenla, J. A. Calleja, J. M.; Ravina, E.; Cortizo, L.; Ceballos, M. L. Biomed. 
Chem. Lett. 1991, 12

13. Osman, R.; Topiol, S.; Rubenstein, L.; Weinstein, H. Mol. Pharmacol. 1987, 32, 699-705.

14. Sleight, A. J.; Peroutka, S. J. Naunyn-Schmiedeberg's Arch Pharmacol. 1991, 343, 109-116.

15. Höltje, H. D.; Briem, H. In QSAR: Rational Approaches to the Design of Bioactive Compounds; Silipo, C.; Vitoria, A., Eds.; Elsevier: Amsterdam, 1991; pp 245-252.

16. Hibert, M. F.; Hoffman, K.; Miller, K. C.; Carr, A. A. J. Med. Chem. 1990, 33, 1594-1600.

17. Cohen, M. L.; Fuller, R. W.; Wiley, K. S. J.Pharmacol. Exp. Ther. $1981,218,421-425$.

18. Fueyo, J.; Raviña, E.; Masaguer, C. F.; Alvarez Casas, J. L.; Alvarez, J.; Rosa, E.; Blanco, T.; Castro, E.; Loza, I.; Fontenla, J. A.; Calleja, J. M. In Proceedings of the VII Meeting of the Spanish Society of Therapeutical Chemistry; Jaca, Spain, 1991; p 71 .

19. Van Rossum, J. M. Arch. Int. Pharmacodyn. 1963, 143, 299-330.

20. Tallarida, R. J.; Murray, R. B. In Manual of Pharmacologic
Calculations with Computer Programs; Springer-Verlag: New York, 1987; pp 53-56.

21. Dewar, M.; Zoebish, E.; Healy, E.; Stewart, J. J. Am. Chem. Soc. 1985, 107, 3902-3909.

22. Dewar, M.; Stewart, J. AMPAC program, QCPE 506, 1986.

23. Frisch, M. J.; Head-Gordon, M.; Trucks, G. W.; Foresman, J. B.; Schlegel, H. B.; Raghavachari, K.; Robb, R.; Binkley, J. S.; Gonzalez, C.; Defrees, D. J.; Fox, D. J.; Whiteside, R. A.; Seeger, R.; Melius, C. F.; Baker, J.; Martin, R. L.; Kahn, L. R.; Stewart, J. J. P.; Topiol, S.; Pople, J. A. GAUSSIAN 90, Revision H; Gaussian Inc.: Pittsburgh, PA, 1990.

24. Sanz, F.; Manaut, F.; José, J.; Segura, J.; Carbó, M.; De la Torre, R. J. Mol. Struct. (THEOCHEM) 1988, 170, 171-180.

\section{Acknowledgments}

This work was supported in part by a CICYT grant (FAR91-1072CO3). The authors thank Marta Pulido, M.D., for editorial assistance. 